\title{
Pengaruh jumlah sudu dan diameter nozel terhadap kinerja turbin pelton
}

\author{
Mafruddin', Rully Meygi Irawan², Nanang Setiawan³, Nurlaila Rajabiah4, Dwi \\ Irawan $^{5^{*}}$
}

\author{
${ }^{1} J u r u s a n T e k n i k$ Mesin, Fakultas Teknik, Universitas Muhammadiyah Metro \\ Jl. Ki Hajar Dewantara 15 A Kota Metro, Lampung, Indonesia \\ *Corresponding author: dwi_irawan12@yahoo.co.id
}

\begin{abstract}
Pelton turbine is one type of impulse turbine that is commonly used in hydroelectric power plants such as micro hydropower plants. The choice of the turbine is based on the high-efficiency generated by the pelton turbine. The main components of the pelton turbine are blades and nozzles. The purpose of this study was to determine the amount of blade and nozzle diameter on the performance of the pelton turbine. The research method was carried out experimentally by design and manufacture of a pelton turbine prototype. Turbines made and protected have specifications of a runner diameter of $150 \mathrm{~mm}$, blade length of $31,1 \mathrm{~mm}$, blade width of 14,6 $\mathrm{mm}$, blade depth of $6,45 \mathrm{~mm}$ and number of nozzles 1 piece. From the results of the study note that the number of blades and diameter of the nozzles affect the power turbine. The highest turbine power is obtained using a number of 21 blades and $8 \mathrm{~mm}$ nozzle diameter of 2,15 Watts. Whereas with the number of blades 19 and $8 \mathrm{~mm}$ nozzle diameter, turbine power is 1,91 Watt, turbine power with 23 blades and $8 \mathrm{~mm}$ nozzle diameter is 1,95 Watts. Turbine power with 19 blades and $10 \mathrm{~mm}$ nozzle diameter is 1,4 Watts, turbine power with 21 nozzles and $10 \mathrm{~mm}$ nozzle diameter is 1,49 Watts and turbine power with 23 blades and $10 \mathrm{~mm}$ nozzle diameter is 1,41 Watts.
\end{abstract}

Keywords: Number of blades, nozzle diameter, pelton turbine performance.

\begin{abstract}
Abstrak
Turbin pelton merupakan salah satu jenis turbin implus yang umum digunakan dalam pembangkit listrik tenaga air seperti pembangkit listrik tenaga mikrohidro. Pemilihan turbin ini didasarkan pada tingginya efisiensi yang dihasilkan turbin pelton. Komponen utama turbin pelton adalah sudu dan nozel. Penelitian ini bertujuan untuk mengetahui pengaruh jumlah sudu dan diameter nozel terhadap kinerja turbin pelton. Metode penelitian dilakukan secara eksperimental dengan melakukan desain dan pembuatan serta pengujian prototipe turbin pelton. Turbin yang dibuat dan diuji memiliki spesifikasi Diameter runner $150 \mathrm{~mm}$, panjang sudu $31,1 \mathrm{~mm}$, lebar sudu 14,6 mm, kedalaman sudu 6,45 mm dan jumlah nozel 1 buah. Dari hasil penelitian diketahui bahwa jumlah sudu dan diameter nozel berpengaruh terhadap daya turbin. Daya turbin tertinggi diperoleh dengan menggunakan jumlah sudu 21 dan diameter nozel $8 \mathrm{~mm}$ sebesar 2,15 Watt. Sedangkan dengan jumlah sudu 19 dan diameter nozel $8 \mathrm{~mm}$ daya turbin 1,91 Watt, daya turbin dengan jumlah sudu 23 dan diameter nozel $8 \mathrm{~mm}$ yaitu 1,95 Watt. Daya turbin dengan jumlah sudu 19 dan diameter nozel $10 \mathrm{~mm}$ yaitu 1,4 Watt, daya turbin dengan jumlah nozel 21 dan diameter nozel $10 \mathrm{~mm}$ yaitu 1,49 Watt dan daya turbin dengan jumlah sudu 23 dan diameter nozel $10 \mathrm{~mm}$ yaitu 1,41 Watt.
\end{abstract}

Kata kunci: Jumlah sudu, diameter nozel, kinerja turbin pelton.

\section{Pendahuluan}

Turbin pelton merupakan salah satu jenis turbin implus yang umum digunakan dalam pembangkit listrik tenaga air seperti pembangkit listrik tenaga mikrohidro. Pemilihan turbin ini didasarkan pada 
tingginya efisiensi yang dihasilkan turbin pelton.

Turbin pelton adalah turbin impuls yang dipakai untuk tinggi air jatuh (head) yang besar. Aliran fluida kerja di dalam pipa akan keluar dengan kecepatan tinggi air jatuh (H) melalui nozel. Tekanan air diubah menjadi kecepatan, pancaran air akan mengenai bagian tengah sudu dan sesuai dengan pertimbangannya tempatnya air pancar akan berbelok dan ada kemungkinan membaliknya air bisa diarahkan tegak lurus. Untuk itu penampang ember dan sudu-sudu nya harus ditinjau agar mendapatkan pemindahan gaya yang sangat baik. Kinerja dari turbin pelton dipengaruhi oleh ketinggian, sudut sudu, jumlah nozel, kecepatan aliran, jumlah sudu dan lainlain. Jumlah sudu turbin pelton adalah suatu variabel yang sangat berpengaruh pada gaya tangensial sehingga resultan gaya yang diperoleh lebih besar memvariasikan jumlah sudu memungkinkan pengurangan besar nilai dari masing-masing gaya tangensial tersebut secara individual namun resultan gaya yang terdapat pada turbin tersebut lebih besar jadi dapat disimpulkan bahwa penambahan jumlah sudu atau memvariasikan jumlah sudu akan menambah putaran dan gaya tangensial yang terjadi dan dengan sendirinya akan meningkatkan daya dan efisiensi turbin pelton [1].

Berdasarkan penelitian terdahulu diketahui bahwa jumlah sudu dan diameter nozel berpengaruh terhadap kinerja turbin pelton. Maka dari itu dalam penelitian ini akan dilakukan desain dan pembuatan serta pengujian turbin pelton. Penelitian ini bertujuan untuk mengetahui pengaruh jumlah sudu dan diameter nozel terhadap kinerja prototipe turbin pelton. Dengan penelitian ini diharapkan dapat meningkatkan kinerja turbin yaitu turbin dengan daya yang tinggi.

\section{Tinjauan Pustaka}

$\begin{array}{cccr}\text { Menurut } & \text { Poea } & \text { dkk } & \text { pada } \\ \text { penelitiannya di tahun } & 2013 \text {, dalam }\end{array}$

perencanaan didapatkan Diameter lingkaran tusuk sebesar $202 \mathrm{~mm}$, diamter jet optimal $71 \mathrm{~mm}$, diameter luar runner sebesar 380,8 mm, jumlah sudu 19 buah dan diameter poros $45 \mathrm{~mm}$ kemudian debit air yang dipakai untuk memutar turbin sebesar $0,06 \mathrm{~m}^{3} / \mathrm{s}$, dengan head efektif $12 \mathrm{~m}$, diperoleh daya aktual yang dihasilkan turbin adalah $4,0 \mathrm{~kW}$, dimana efisiensi total sebesar $60 \%$ [2].

Penelitian yang dilakukan oleh Riandi pada tahun 2016, memvariasaikan jumlah sudu yaitu 13 dan 16 sudu. Daya mekanik maksimum diperoleh dengan menggunakan sudu 16 buah pada putaran 604 rpm dengan perolehan daya mekanik sebesar 180,8 Watt, sedangkan daya mekanik minimum di peroleh dengan menggunakan jumlah sudu 13 buah pada putaran $305 \mathrm{rpm}$ dengan perolehan daya mekanik sebesar 108,5 Watt. Dan hasil penelitian menunjukan adanya pengaruh jumlah sudu terhadap daya dengan efisiensi turbin pelton yaitu sudu 16 mempunyai daya dan efisiensi lebih tinggi dibandingkan dengan jumlah sudu 13 buah dan pada jumlah sudu 16 buah daya dan efisiensi meningkat pada 180,8 Watt dengan efisiensi $82 \%$ sedangkan sudu 13 buah daya yang di peroleh 108,5 Watt dengan efisiensi 49\% [3].

Penelitian yang dilakukan oleh Rosmiati dan Yani di tahun 2017, dengan variasi nozel yaitu 1 inchi, $3 / 4$ inchi, $1 / 2$ inchi, dan $1 / 3$ inchi. Torsi turbin maksimum terjadi pada diameter nozel $1 / 3$ inchi dengan nilai sebesar $0,645 \mathrm{Nm}$, kemudian torsi kedua pada diameter nozel $1 / 2$ inchi dengan nilai sebesar $0,555 \mathrm{Nm}$, torsi turbin ketiga terjadi pada diameter nozel $3 / 4$ inchi dengan nilai sebesar $0.345 \mathrm{Nm}$, dan torsi turbin terendah terjadi pada diameter nozel 1 inchi dengan nilai sebesar $0,165 \mathrm{Nm}$. Daya turbin maksimum terjadi pada diameter nozel $1 / 3$ inchi dengan nilai sebesar 5,966 Watt, kemudian daya turbin urutan kedua terjadi pada diameter nozel $1 / 2$ inchi dengan nilai sebesar 5,338 Watt, kemudian daya turbin urutan ketiga terjadi pada diameter nozel $3 / 4$ inchi dengan nilai sebesar 1,413 
Watt, dan daya turbin terendah terjadi pada diameter nozel 1 inchi dengan nilai sebesar 0,864 Watt [4].

Pada tahun 2018, Mafruddin dan

Dwi Irawan melakukan penelitian tentang pengaruh diameter dan jumlah sudu runner terhadap kinerja turbin crossflow. Dari hasil penelitian diketahui bahwa variasi jumlah sudu berpengaruh terhadap karakter efisiensi turbin. Dapat diketahui bahwa efisiensi pada turbin berbeda-beda pada setiap putaran turbin. Efisiensi turbin tertinggi diperoleh pada putaran $175 \mathrm{rpm}$, sedangkan putaran turbin semakin rendah maupun semakin tinggi efisiensi turbin cenderung lebih rendah [5].

Kecepatan keliling runner suatu turbin pelton dapat dihitung menggunakan persamaan berikut [6].

$$
\mathrm{U}_{1}=\mathrm{K}_{\mathrm{u}} \sqrt{2 . \mathrm{g} \mathrm{Hn}}
$$

Keterangan :

$\mathrm{U}_{1}=$ Kecepatan keliling optimal $(\mathrm{m} / \mathrm{s})$

$\mathrm{K}_{\mathrm{u}}=$ Koefisien keliling optimal $(0,45-$ $0,49)$

$\mathrm{H}_{\mathrm{n}}=$ Head net $(\mathrm{m})$

Diameter lingkaran tusuk dapat dihitung dengan persamaan :

$$
D l t=\frac{60 U_{1}}{\pi \cdot n}
$$

Keterangan :

$D l t=$ Diameter lingkaran tusuk $(\mathrm{mm})$

$U_{1}=$ Kecepatan keliling optimal $(\mathrm{m} / \mathrm{s})$

$n=$ putaran poros (rpm)

Untuk menentukan jumlah bucket

(sudu) optimal digunakan persamaan berikut:

$$
\mathrm{z}=5,4 \frac{\sqrt{D l t}}{d n}
$$

Keterangan :

$$
\begin{aligned}
& \mathrm{Z} \quad=\text { Jumlah sudu } \\
& D l t=\text { Diameter lingkar tusuk }(\mathrm{mm}) \\
& d n=\text { diameter nozel (mm) } \\
& \quad \text { Dimensi-dimensi bucket (sudu) }
\end{aligned}
$$
dapat dihitung dengan rumus berikut:

Lebar mangkuk

$$
B_{s}=(4-5) d_{n}
$$

Tinggi mangkuk

$$
L_{s}=(2,4-3,2) d_{n}
$$

Lebar celah mangkuk

$$
M=(1,1-1,25) d_{n}
$$

Kedalaman mangkuk

$$
C_{s}=(0,81-1,05) d_{n}
$$

Untuk menentukan

diameter pancaran air atau nozel maksimum digunakan persamaan:

$$
d n=0,52 \sqrt{\frac{Q}{\sqrt{H}}}
$$

Keterangan :

$$
\begin{aligned}
& d n=\text { Diameter nozel }(\mathrm{mm}) \\
& \mathrm{Q}=\operatorname{Kapasitas} \text { air }\left(\mathrm{m}^{3} / \mathrm{s}\right) \\
& \mathrm{H}=\operatorname{Head}(\mathrm{m})
\end{aligned}
$$

Sedangkan untuk kecepatan mutlak Jet (nozel) munggunakan persamaan :

$$
\mathrm{C}_{1}=\mathrm{Kc} \sqrt{2 \cdot g \cdot H n}
$$

Keterangan :

$$
\mathrm{C}_{1}=\text { Kecepatan mutlak jet }(\mathrm{m} / \mathrm{s})
$$

Kc $=$ Koefisien Jet $(0,96-0,98)$

$g=$ Gravitasi $\left(\mathrm{m}^{2} / \mathrm{s}\right)$

$H n=$ Head Net (m)

Daya yang dihasilkan turbin dapat diketahui dengan persamaan berikut.

$$
P_{t}=T . \omega
$$

Keterangan :

$$
\begin{aligned}
& P_{t}=\text { Daya Turbin }(\text { Watt }) \\
& T=\text { Torsi }(\mathrm{Nm}) \\
& \omega=\text { Kecepatan Keliling }(\mathrm{rad} / \mathrm{s})
\end{aligned}
$$

\section{Metode Penelitian}

Lokasi penelitian dilakukan di Laboratorium Teknik Mesin Universitas Muhammadiyah Metro. Penelitian ini dilakukan dengan metode eksperimen nyata (true experimental research) dengan variasi jumlah sudu $(19,21$, dan 23$)$ dan variasi diameter nozel $(8 \mathrm{~mm}$ dan $10 \mathrm{~mm})$. Debit air yang digunakan pada pengujian turbin yaitu 17,2 lpm.

Metode penelitian meliputi tahap persiapan, pembuatan turbin, sampai dengan mengujian prototipe turbin.

Parameter dimensi turbin pelton yang dibuat dan diuji yaitu sebagai berikut.

Tabel 1. Parameter dimensi turbin pelton

\begin{tabular}{clc}
\hline No. & \multicolumn{1}{c}{ Parameter } & Nilai \\
\hline 1 & Diameter Runner & $150 \mathrm{~mm}$ \\
2 & Panjang sudu & $31.1 \mathrm{~mm}$ \\
3 & Lebar sudu & $14.6 \mathrm{~mm}$ \\
4 & Kedalaman sudu & $6.45 \mathrm{~mm}$ \\
5 & Jumlah Nozel & 1 \\
\hline
\end{tabular}


Pengujian turbin dilakukan dengan metode pengereman menggunakan rem cakram (Disc Brake). Pembacaan beban rem dilakukan dengan loadcell untuk mengetahui gaya yang dihasilkan turbin pelton.

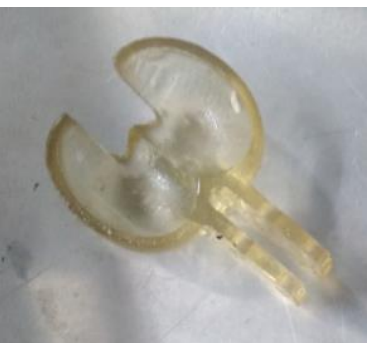

Gambar 1. Sudu turbin pelton

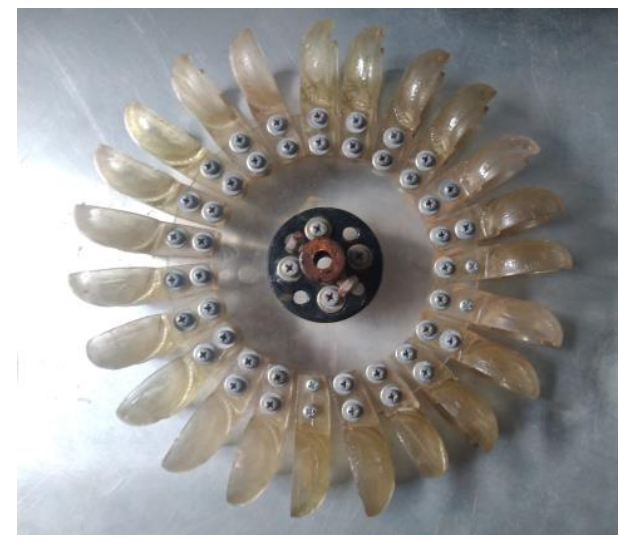

Gambar 2. Runner turbin pelton

\section{Hasil dan Pembahasan}

Berdasarkan hasil pengujian daya turbin pelton dengan variasi jumlah sudu dan diameter nozel diperoleh karakteristik daya yang dihasilkan sebagai berikut.

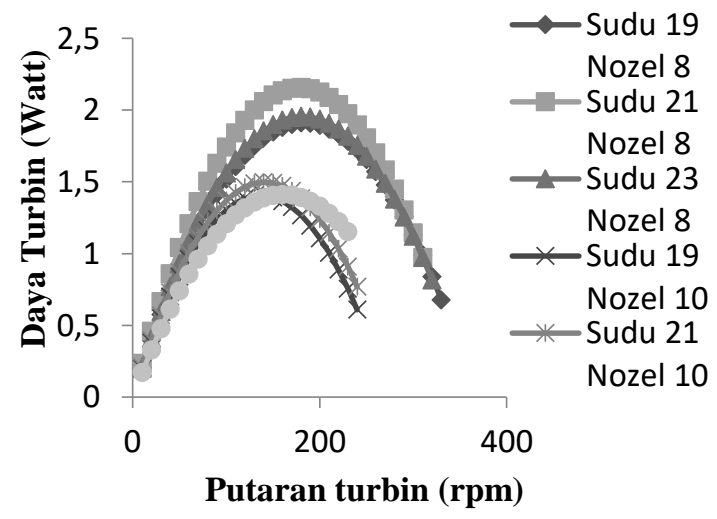

Gambar 3. Pengaruh jumlah sudu dan diameter nozel terhadap daya turbin

Berdasarkan Gambar 3, pengaruh jumlah sudu dan diameter nozel terhadap daya turbin dapat diketahui bahwa variasi jumlah sudu dan diameter nozel berpengaruh terhadap karakter daya turbin. Daya yang dihasilkan turbin mempunyai pola yang sama namun untuk daya maksimal yang dihasilkan turbin pelton bervariasi.

Berikut merupakan daya maksimal yang dihasilkan turbin dengan variasi jumlah sudu dan diameter nozel.

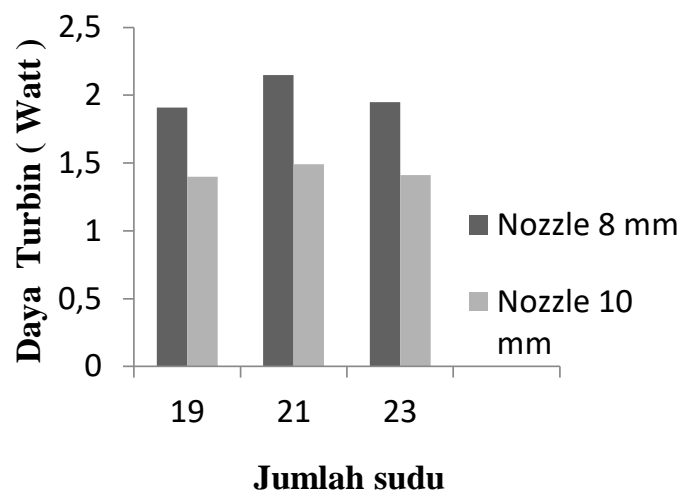

Gambar 4. Pengaruh jumlah sudu dan diameter nozel terhadap daya turbin

Berdasarkan Gambar 4. Pengaruh jumlah sudu dan diameter nozel terhadap daya turbin dapat diketahui bahwa jumlah sudu dan diameter nozel berpengaruh terhadap daya turbin pelton. Daya turbin tertinggi diperoleh dengan menggunakan jumlah sudu 21 dan diameter nozel $8 \mathrm{~mm}$ sebesar 2,15 Watt. Sedangkan dengan jumlah sudu 19 dan diameter nozel $8 \mathrm{~mm}$ daya turbin 1,91 Watt, daya turbin dengan jumlah sudu 23 dan diameter nozel $8 \mathrm{~mm}$ yaitu 1,95 Watt.

Daya yang dihasilkan turbin menggunakan diameter nozel $10 \mathrm{~mm}$ lebih rendah dibandingkan dengan menggunakan diameter nozel $8 \mathrm{~mm}$. Daya turbin dengan jumlah sudu 19 dan diameter nozel $10 \mathrm{~mm}$ yaitu $1,4 \mathrm{Watt}$, daya turbin dengan jumlah nozel 21 dan diameter nozel $10 \mathrm{~mm}$ yaitu 1,49 Watt dan daya turbin dengan jumlah sudu 23 dan diameter nozel $10 \mathrm{~mm}$ yaitu $1,41 \mathrm{Watt}$.

Daya yang dihasilkan turbin pelton diperoleh dari momentum yang dihasilkan oleh air yang keluar dari nozel, semakin tinggi kecepatan air dengan massa yang sama maka momentum air semakin tinggi. 
Perubahan momentum air yang menumbuk sudu turbin akan menghasilkan gaya dorong pada turbin, sehingga dengan kecepatan air yang tinggi akan menghasilkan daya turbin yang tinggi. Berdasarkan prinsip kontinuitas pada suatu aliran dalam pipa, semakin kecil suatu luas saluran (diameter) maka kecepatan aliran akan meningkat.

Hasil penelitian menunjukan pola yang selaras seperti pada penelitian yang dilakukan oleh Rosmiati dan Yani (2017) [4] bahwa daya yang dihasilkan turbin pelton semakin meningkat dengan diameter nozel yang semakin kecil. Karakter daya dihasilkan turbin pelton sama seperti karakter daya yang dihasilkan turbin crossflow. Turbin menghasilkan efisiensi maksimal pada putaran tertentu. Semakin besar beban yang diberikan pada turbin maka daya turbin semakin turun.

\section{Kesimpulan}

Dari hasil penelitian diketahui bahwa jumlah sudu dan diameter nozel berpengaruh terhadap daya turbin. Daya turbin maksimal diperoleh dengan menggunakan jumlah sudu 21 dan diameter nozel $8 \mathrm{~mm}$ sebesar 2,15 Watt. Sedangkan dengan jumlah sudu 19 dan diameter nozel $8 \mathrm{~mm}$ daya turbin 1,91 Watt, daya turbin dengan jumlah sudu 23 dan diameter nozel $8 \mathrm{~mm}$ yaitu 1,95 Watt. Daya turbin dengan jumlah sudu 19 dan diameter nozel $10 \mathrm{~mm}$ yaitu $1,4 \mathrm{Watt}$, daya turbin dengan jumlah nozel 21 dan diameter nozel $10 \mathrm{~mm}$ yaitu 1,49 Watt dan daya turbin dengan jumlah sudu 23 dan diameter nozel $10 \mathrm{~mm}$ yaitu $1,41 \mathrm{Watt}$.

\section{Referensi}

[1] Irawan, D. (2014). Prototype Turbin Pelton Sebagai Energi Alternatif Mikrohidro Di Lampung. Turbo: Jurnal Program Studi Teknik Mesin, 3(1).

[2] Poea, C. S., Soplanit, G. D., \& Rantung, J. (2013). Perencanaan Turbin Air Mikro Hidro Jenis Pelton
Untuk Pembangkit Listrik Di Desa Kali Kecamatan Pineleng Dengan Head 12 Meter. Jurnal Online Poros Teknik Mesin Unsrat, 1(1).

[3] Nurman, R. (2017). Analisis Sistem Pembangkit Energi Listrik 240 Volt Di Plth Pandansimo Yogyakarta Dan Simulasi Menggunakan Software Homer.

[4] Rosmiati Dan Yani, A. 2017. Pengaruh Variasi Diameter Nosel Terhadap Torsi Dan Daya Turbin Air. .Turbo; Jurnal Teknik Mesin Univ. Muhammadiyah Metro. Vol. 6 No. 1. 2017.

[5] Mafruddin, M., \& Irawan, D. (2018). Pengaruh Diameter Dan Jumlah Sudu Runner Terhadap Kinerja Turbin Cross-Flow. Turbo: Jurnal Program Studi Teknik Mesin, 7(2).

[6] Eisenring, M. 1994. Turbin Pelton Mikro, terjemahan Sunarto, Edy. M. Jakarta. 